Review Article

\title{
Prevalence, management and outcome of cryptorchidism associated with gastroschisis: A systematic review and meta-analysis
}

\author{
Silvia Ceccanti ${ }^{\mathrm{a}}$, Giuseppe Migliara ${ }^{\mathrm{b}}$, Corrado De Vito ${ }^{\mathrm{b}}$, Denis A. Cozzi ${ }^{\mathrm{a}, *}$ \\ a Pediatric Surgery Unit, Department of Maternal Infantile and Urological Sciences, Sapienza University of Rome, Azienda Ospedaliero Universitaria \\ Policlinico Umberto I, Viale Regina Elena, 324, Rome 00161, Italy \\ ${ }^{\mathrm{b}}$ Department of Public Health and Infectious Diseases, Sapienza University of Rome, Italy
}

\section{A R T I C L E I N F O}

\section{Article history:}

Received 27 April 2021

Revised 6 June 2021

Accepted 5 July 2021

Available online $\mathrm{xxx}$

\section{Keywords:}

Gastroschisis

Cryptorchidism

Undescended testis

Prolapsed testis

Neonate

Orchiopexy

Testicular atrophy

\begin{abstract}
A B S T R A C T
Purpose: Cryptorchidism associated with gastroschisis has been poorly investigated. We aimed to assess the prevalence of this association, and to address the management and outcome of cryptorchidism in this context.

Materials and methods: In this systematic review, we searched electronic databases (PubMed, Web of Science, and Google Scholar), without language restrictions from inception to March 31, 2021, for studies on cryptorchidism and gastroschisis co-occurrence. Random effects meta-analysis was used to calculate pooled prevalence estimates of cryptorchidism in gastroschisis and spontaneous testicular descent in this population.

Results: Twenty-five studies were included for the systematic review. All were retrospective case reports or series for a total of 175 patients. Pooled prevalence estimate for cryptorchidism in gastroschisis was $19 \%$ (95\% CI 13-26). Complete data sets for management and outcome analysis were available in 94 patients, involving 120 undescended testes [63 (52.5\%) nonpalpable, 34 (28.3\%) prolapsed outside the abdominal wall defect, and 23 (19.2\%) palpable]. Fifty-five descended spontaneously, with a pooled prevalence estimate of $50 \%$ (95\% CI 31-69). Twelve testes/remnants were primarily removed or absent, while 49 testes underwent orchiopexy (success rate, 63\%). Excluding 4 testes still awaiting orchiopexy, 30 of the remaining $116(25.8 \%)$ testes had a dismal outcome, including testicular loss (19), hypoplasia (8) or recurrent cryptorchidism (3).

Conclusion: Cryptorchidism in gastroschisis appears to occur more frequently than in the normal population. The overall mediocre testicular outcome seems to reflect the most unfavorable presentation of cryptorchidism in gastroschisis, which is represented by originally intrabdominal or prolapsed testis in the majority of cases.
\end{abstract}

Level of evidence: IV.

(C) 2021 Elsevier Inc. All rights reserved.

\section{Introduction}

Gastroschisis is a rare congenital malformation where internal organs extend outside of the abdomen through a hole next to the belly button, occurring in about 1 of every 6000 births.

In contrast, cryptorchidism is the most common birth defect of the male genitourinary tract, affecting approximately $3 \%$ to $5 \%$ of full-term neonates, with an even higher incidence in premature and low birth weight neonates. ${ }^{1,2}$ This condition, also commonly known as undescended testis (UDT), is characterized by a failure of one or both testes to descend into the scrotum.

Notably, the coexistence of the two malformations has been scarcely reported in the literature, so that the extent of this association yet remains to be determined. Likewise, also existing data on

\footnotetext{
* Corresponding author.

E-mail address: da.cozzi@uniroma1.it (D.A. Cozzi).
}

the management of cryptorchidism in gastroschisis are scattered, and derive from underpowered studies, thus precluding inferences for clinical practice. Interestingly, cryptorchidism in gastroschisis may have a unique extra-abdominal presentation, that is when the affected testis is prolapsed outside of the abdominal wall defect along with other abdominal organs.

Therefore, the aim of this systematic literature review and meta-analysis is to provide an overview of the published evidence focusing on prevalence, management and outcome of cryptorchidism associated with gastroschisis.

\section{Materials and methods}

\subsection{Search strategy $\mathcal{E}$ selection criteria}

This systematic review was conducted according to the Preferred Reporting Items for Systematic Reviews and Meta-Analyses (PRISMA) statement. ${ }^{3}$ 
We searched the following electronic databases for reports published on the co-occurrence of gastroschisis and cryptorchidism from inception to March 31, 2021: PubMed, Web of Science, and Google Scholar. The following MeSH (medical subject heading) terms or keywords were used in combination for search in titles or abstracts: "gastroschisis", "abdominal wall defects", "testes", "cryptorchidism", and "undescended testis". We did not apply any language or publication type restrictions. We also hand-searched the reference lists of retrieved publications to further increase our yield of potentially relevant articles. Articles that were clearly irrelevant were excluded after examination of titles and abstracts. Fulltext versions of the articles potentially suitable for inclusion were retrieved and evaluated against the selection criteria. Two reviewers undertook the study selection, data extraction, and quality assessment independently. Disagreements regarding eligibility were resolved by consensus or by consulting a third investigator.

\subsection{Outcomes of interest and definitions} ysis:

The following outcomes and definitions were used in this anal-

1) Prevalence of cryptorchidism in gastroschisis was defined as the number of cryptorchidism cases existing at a given time in a given male population of gastroschisis, and was expressed as a percentage.

2) Cryptorchidism was classified as palpable, nonpalpable, and prolapsed according to the location of affected testis determined at birth. Amongst the nonpalpable cryptorchidism category are included intrabdominal, atrophic, remnant or absent testes. Prolapsed testis, which represents a unique extraabdominal presentation of cryptorchidism in gastroschisis, was defined as a testis protruding outside of the abdominal wall defect.

3) Prematurity was defined as gestational age $<37$ weeks.

4) The timing of surgery was defined early when any surgical intervention was performed at birth or within the first 3 months of life.

5) Spontaneous testicular descent was defined as an originally UDT undergoing spontaneous descent into the scrotum ascertained at any time from neonatal period onwards.

6) Successful orchiopexy was defined as an operated testis normal in size and location at follow-up.

7) Dismal testicular outcome was defined as testicular loss (congenital or acquired), testicular hypoplasia, or recurrent UDT.

\subsection{Data extraction and quality assessment}

Included studies were categorised by study design. Data extraction was carried out using predesigned data extraction forms for each study design. Data were extracted on the key study characteristics, design, methods of data collection, participant characteristics, results and conclusions drawn by authors. Studies were grouped into levels of evidence, which was graded using the Oxford centre for Evidence-Based Medicine scale (CEBM). ${ }^{4}$

When all included studies were non-randomized, the quality of articles was appraised using the Methodological Index for NonRandomized Studies (MINORS) checklist. ${ }^{5}$ This validated scoring tool involves 12 items: the first 8 specifically designed for noncomparative studies and additional 4 items applied to comparative studies. The items are scored as 0 (not reported), 1 (reported but inadequate) or 2 (reported and adequate). As such, the maximum possible score is 16 for non-comparative studies and 24 for comparative studies. Scores are added and total scores converted to a percentage of the maximal possible score. Consensus was employed to resolve any disagreements. Additionally, we adopted the validated Surgical Case Report (SCARE) 2018 checklist for overall judgement about methodological quality of included case reports. ${ }^{6}$ Finally, an attempt was made to contact study authors by email for missing data considered important for evaluating key study findings.

\subsection{Statistical analysis}

Inverse-variance random-effects meta-analyses were used to calculate pooled prevalence estimates of cryptorchidism in gastroschisis and spontaneous testicular descent in this population across studies with the associated 95\% confidence intervals, respectively. The Freeman-Tukey double arcsine transformation was used to stabilize the variance of the prevalence estimates. The $\mathrm{I}^{2}$ metric was used to test for heterogeneity. We also analyzed the effect of the stratification for prematurity in the model for the pooled prevalence estimate of cryptorchidism in gastroschisis. Included studies were stratified based on the median or mean gestational age reported, using a cut-off of $<37$ weeks. The analysis of the data consisted of descriptive statistics, providing numbers and percentages for qualitative variables and median (range) for quantitative variables. We used the Chi-square test for trend to test the frequency distribution of binary variables among the 3 patient subgroups. Significance was assumed at $p<0.05$. Meta-analyses were performed using Stata 15.1 (StataCorp LLC, 4905 Lakeway Drive, College Station, Texas, USA).

\section{Results}

\subsection{Literature search and study characteristics}

The systematic electronic search identified a total of 115 relevant articles related to cryptorchidism and gastroschisis. Further 6 studies were identified through the hand search and crossreferencing. In total, 25 studies fulfilled the selection criteria and were included in the analysis. Fig. 1 shows the study flow diagram. There were 175 patients reported with the co-occurrence of cryptorchidism and gastroschisis (Table 1). All included studies were retrospective case series $(n=20)^{7-26}$ or case reports $(n=5)^{27-31}$ (Level IV). ${ }^{4}$ Included articles were published between 1986 and 2021. Patients had been operated between 1974 and 2016. All studies were single center-based series, except one multicenternational register study. ${ }^{26}$ Comparison using the MINORS checklist showed consistency in the quality of the 20 reviewed case series studies, with a median score of 62.5 per cent of the best possible score (range, 46 to 75 ; 95\% CI 58.13-65.77) (Table 1). Of these studies, 7 were comparative studies ${ }^{7,12,16,17,24,25,26}$. However, the object of comparison was irrelevant to our outcomes of interest in all, including also two studies that used historical controls. ${ }^{7,17}$ Ten (50\%) studies did not perform any statistical analyses, whereas all others performed uni- and bivariate analyses with reported $p$ values. Of these, 2 studies included multivariate analysis, and 3 reported confidence intervals or relative risks. Finally, the 5 included case reports adequately complied with the requirements of the SCARE 2018 checklist with regard to clinical characteristics, management and outcome details, which were implemented by contact of the study authors in three. $23,28,31$

Overall, 19 studies reported raw numbers that allowed the calculation of a prevalence estimate in a given time period of cryptorchidism in male patients with gastroschisis, and therefore were entered into the quantitative synthesis ${ }^{3,4,10-21,23-26,31}$. One of these studies included 1 patient who died shortly after birth and, therefore, was excluded from further analysis. ${ }^{20}$ Fourteen studies detailed clinical characteristics, management and outcome of cryptorchidism in gastroschisis, and were entered into the qualitative synthesis. ${ }^{3,4,11,13,14,19-22,27-31}$ 
Table 1

Characteristics of original studies included in analysis

\begin{tabular}{|c|c|c|c|c|c|c|c|c|}
\hline Author, year & Design & $\begin{array}{l}\text { Males with } \\
\text { Gastroschisis (n) }\end{array}$ & $\begin{array}{l}\text { No. of Patients/ } \\
\text { No. of testes }\end{array}$ & $\begin{array}{l}\text { Gestational age } \\
(\text { weeks)* }\end{array}$ & $\begin{array}{l}\text { UDT classification } \\
\text { (n) }\end{array}$ & Management ( $\mathrm{n}$ of testis) & $\begin{array}{l}\text { Dismal Outcome } \\
\text { (n of testis) }\end{array}$ & MINORS \\
\hline Kaplan et al. $1986^{7}$ & Case series & 28 & $5 / 8$ & 2 prematures & - & - & - & $17(71 \%)$ \\
\hline Gauderer et al. $1987^{8}$ & Case series & - & $3 / 3$ & $33.6(28-38)$ & Prolapsed (3) & $\begin{array}{l}\text { Early orchiopexy ( } 3) \text { - two-stage } \\
\text { orchiopexy at } 2 \text { years ( } 1 \text { ) }\end{array}$ & $\begin{array}{l}\text { Testicular } \\
\text { hypoplasia (2) }\end{array}$ & $10(62.5 \%)$ \\
\hline Aliotta et al. $1992^{9}$ & Case series & 12 & 3/- & All premature & - & - & - & $8(50 \%)$ \\
\hline Levard et al. $1997^{10}$ & Case series & 10 & $4 / 5$ & $38(35-41)$ & Nonpalpable (5) & Early orchiopexy (3) - Orchiopexy (2) & $\begin{array}{l}\text { Recurrent UDT } \\
\text { (2), one of which } \\
\text { slightly smaller }\end{array}$ & $12(75 \%)$ \\
\hline Koivusalo et al., $1998^{11}$ & Case series & 38 & $2 / 2$ & 35,37 & $\begin{array}{l}\text { Nonpalpable (1) } \\
\text { Palpable (1) }\end{array}$ & Orchiopexy (2) & - & $9(56 \%)$ \\
\hline Kumar et al., $1999^{12}$ & Case series & 25 & 8/- & - & - & - & - & $16(66.6 \%)$ \\
\hline Chowdhary et al., $2001^{13}$ & Case series & 16 & $5 / 8$ & - & $\begin{array}{l}\text { Prolapsed (3) } \\
\text { Nonpalpable (5) }\end{array}$ & $\begin{array}{l}\text { Spontaneous descent (7) - Palpable UDT } \\
\text { awaiting orchiopexy (1) }\end{array}$ & - & $10(62.5 \%)$ \\
\hline Lawson et al., $2001^{14}$ & Case series & 50 & $16 / 20$ & $36.33 \pm 1.7$ & $\begin{array}{l}\text { Prolapsed (10) } \\
\text { Nonpalpable (10) }\end{array}$ & $\begin{array}{l}\text { Spontaneous descent (10) - Early } \\
\text { orchiopexy (2) - Orchiopexy (4) - } \\
\text { Orchiectomy (3) - Absent testis (1) }\end{array}$ & $\begin{array}{l}\text { Recurrent UDT } \\
\text { (1) - Testicular } \\
\text { atrophy (1) }\end{array}$ & $10(62.5 \%)$ \\
\hline Pringle et al., $2001^{27}$ & Case report & - & $2 / 2$ & 34,38 & Prolapsed (2) & $\begin{array}{l}\text { Spontaneous descent (1) - Early } \\
\text { orchiopexy (1) }\end{array}$ & & $\mathrm{n} / \mathrm{a}$ \\
\hline Wakefield et al., $2002^{28}$ & Case report & - & $1 / 2$ & 37 & Prolapsed (2) & Early orchiopexy (2) & $\begin{array}{l}\text { Recurrent UDT \& } \\
\text { testicular } \\
\text { hypoplasia (2) }\end{array}$ & $\mathrm{n} / \mathrm{a}$ \\
\hline Bratemberg et al., $2004^{15}$ & Case series & 30 & $2 / 2$ & - & - & - & - & $9(56 \%)$ \\
\hline Hwang et al., $2004^{16}$ & Case series & 35 & $6 /-$ & - & - & - & - & $11(46 \%)$ \\
\hline Kunz et al., $2005^{17}$ & Case series & 294 & 19/- & - & - & - & - & $12(50 \%)$ \\
\hline Eggink et al., $2006^{18}$ & Case series & 29 & $5 /-$ & - & - & - & - & $9(56 \%)$ \\
\hline Berger et al., $2006^{19}$ & Case series & 26 & $7 / 7$ & $38(35-41)$ & $\begin{array}{l}\text { Prolapsed (4) } \\
\text { Nonpalpable (3) }\end{array}$ & $\begin{array}{l}\text { Spontaneous descent (1) - Early } \\
\text { orchiopexy (2) - Early orchiectomy (1) - } \\
\text { Removal of testicular remnant (1) - } \\
\text { Orchiopexy (2) }\end{array}$ & $\begin{array}{l}\text { Testicular } \\
\text { atrophy (2) }\end{array}$ & $10(62.5 \%)$ \\
\hline Muensterer et al., $2011^{29}$ & Case report & - & $1 / 1$ & 35 & Nonpalpable (1) & $\begin{array}{l}\text { Single-stage laparoscopic Fowler-Stephens } \\
\text { orchiopexy (1) }\end{array}$ & - & $\mathrm{n} / \mathrm{a}$ \\
\hline Hill et al., $2012^{20}$ & Case series & 62 & $24 \dagger / 31$ & $36 \pm 1.9$ & $\begin{array}{l}\text { Prolapsed (4) } \\
\text { Nonpalpable (27) }\end{array}$ & $\begin{array}{l}\text { Spontaneous descent (17) - Early } \\
\text { orchiopexy (1) - Orchiopexy (11) - } \\
\text { Removal of atrophic testis (2) }\end{array}$ & $\begin{array}{l}\text { Testicular } \\
\text { hypoplasia (3) - } \\
\text { Testicular } \\
\text { atrophy (1) }\end{array}$ & $10(62.5 \%)$ \\
\hline Yardley et al., $2012^{21}$ & Case series & 79 & $26 / 35$ & $36(33-39)$ & $\begin{array}{l}\text { Prolapsed (2) } \\
\text { Nonpalpable (11) } \\
\text { Palpable (22) }\end{array}$ & $\begin{array}{l}\text { Spontaneous descent (18) - Orchiopexy } \\
\text { (11) - Absent testis (2) - Orchiectomy (1) } \\
\text { - Awaiting orchiopexy (3) }\end{array}$ & $\begin{array}{l}\text { Testicular } \\
\text { atrophy (3) - } \\
\text { Testicular } \\
\text { hypoplasia (1) }\end{array}$ & $10(62.5 \%)$ \\
\hline Patel et al., $2013^{30}$ & Case report & - & $1 / 1$ & 37 & Prolapsed (1) & $\begin{array}{l}\text { Early removal of vanishing testis in } \\
\text { closing gastroschisis (1) }\end{array}$ & - & $\mathrm{n} / \mathrm{a}$ \\
\hline Vila-Carbó et al., $2013^{22}$ & Case series & - & $2 / 2$ & 36,37 & Prolapsed (2) & Orchiopexy (2) & - & $12(75 \%)$ \\
\hline Corona-Rivera et al., $2015^{23}$ & Case series & 52 & $13 / 18$ & $35.84(30-40)$ & - & - & - & $10(62.5 \%)$ \\
\hline Watanabe et al., $2017^{24}$ & Case series & 8 & $1 /-$ & Premature & - & - & - & $15(62.5 \%)$ \\
\hline Koehler et al., $2017^{25}$ & Case series & 86 & $8 /-$ & All premature & - & - & - & $18(75 \%)$ \\
\hline Ceccanti et al., $2020^{31}$ & Case report & 3 & $1 / 1$ & 34 & Prolapsed (1) & Spontaneous descent (1) & - & $\mathrm{n} / \mathrm{a}$ \\
\hline Raitio et al., $2021^{26}$ & Case series & 99 & $10 / 11$ & $36.7 \pm 1.9$ & - & - & - & $15(62.5 \%)$ \\
\hline
\end{tabular}

UDT, undescended testis.

MINORS: Methodological Index for Non-Randomized Studies.

n/a, not applicable.

*Data reported as mean (range), mean $\pm \mathrm{SD}$ or $\mathrm{n}$.

$\dagger 1$ early death excluded from further analysis. 

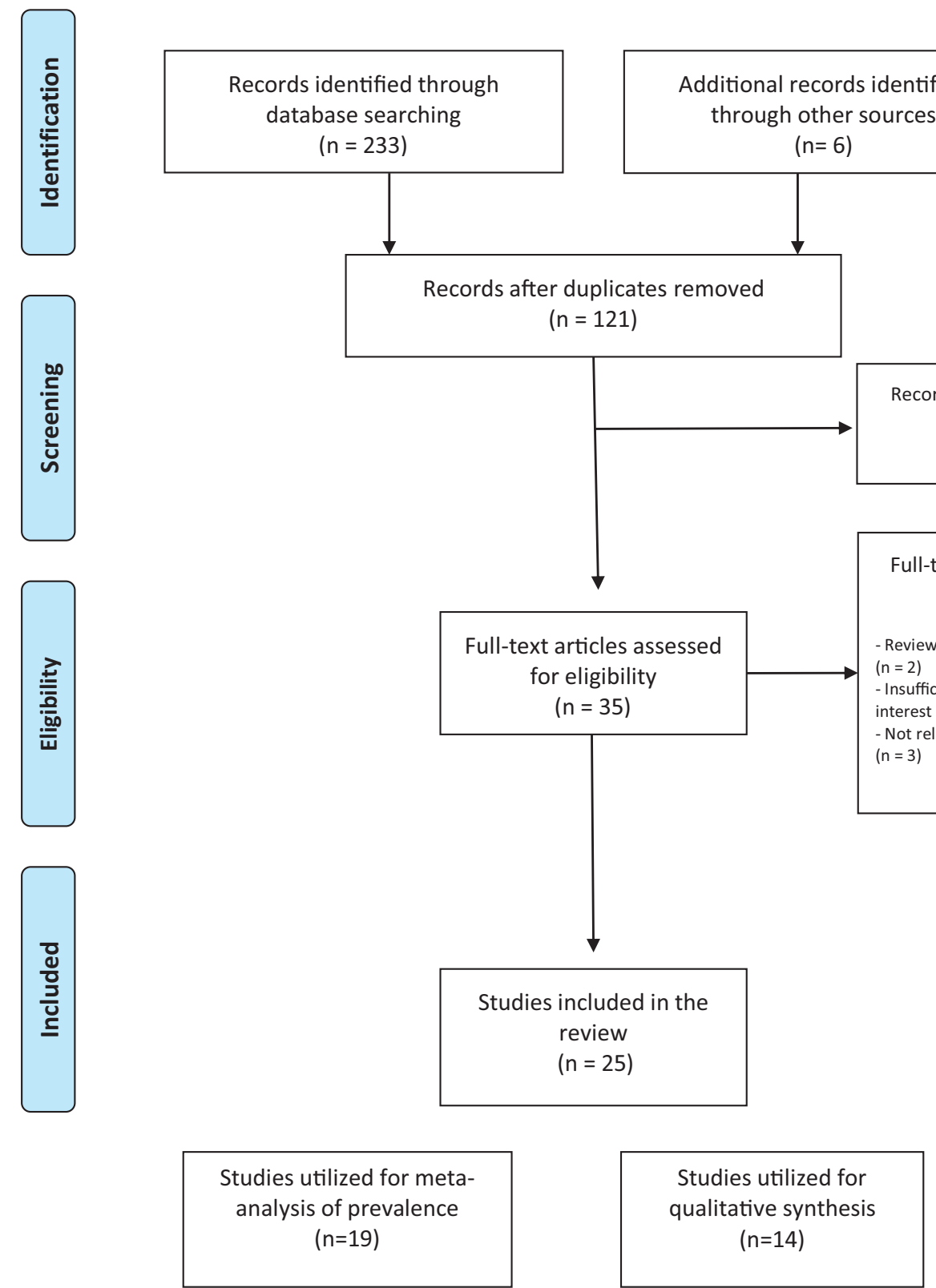

Fig. 1. Flow diagram of systematic review of literature using PRISMA.

\subsection{Quantitative synthesis}

\subsection{Prevalence of cryptorchidism in gastroschisis}

Nineteen studies were eligible for the meta-analysis of the pooled prevalence estimate of cryptorchidism in gastroschisis. ${ }^{7,9-21,23-26,31}$ The model reported a high level of heterogeneity between the studies ( $\mathrm{I}^{2} 80,6 \%$ ), yielding a pooled prevalence of $19 \%$ (95\% CI 13-26\%) (Fig. 2). Of these studies, thirteen ${ }^{7,9-11,14,19-21,23-26,30}$ reported information about gestational age and were used for the meta-analysis stratified by prematurity. The model showed a pooled prevalence estimates of $24 \%$ for full-terms (95\% CI 14-36\%), $, 10,19$ and of $20 \%$ for prematures (95\% CI 11-30\%), ${ }^{9,11,14,20,21,23-26,30}$ with an overall pooled prevalence estimate of $2 \%\left(95 \%\right.$ CI 13-29\%; I ${ }^{2}$ 75\%) (Fig. 3). Eleven studies were eligible for the meta-analysis of the pooled prevalence estimate of spontaneous testicular descent in gastroschisis. ${ }^{10,11,13,14,19-22,27,29,31}$ The model reported a low level of het- erogeneity between the studies $\left(\mathrm{I}^{2} 35,8 \%\right)$, yielding a pooled prevalence of 50\% (95\% CI 31\%-69\%) (Fig. 4).

\subsection{Qualitative synthesis}

\subsection{Management and outcome of cryptorchidism in gastroschisis}

Complete data sets for management and outcome analysis were available in 94 patients, involving 120 UDT ( 26 bilateral cases). Of these, 63 (52.5\%) were nonpalpable, 34 (28.3\%) were prolapsed, and 23 (19.2\%) were palpable testes (Fig. 5). Premature birth occurred in the vast majority of patients (Table 1). Sixteen (13.3\%) testes underwent initial operative management. Of these, 2 prolapsed testes were removed for extremely short testicular vessels or vanishing testis, respectively. ${ }^{19,30}$ Fourteen testes underwent early orchiopexy, including 11 at the time of initial gastroschisis repair, and 3 during ipsilateral $(2)^{10,27}$ or contralateral $(1)^{20}$ inguinal hernia repair performed between 2 and 3 months of age. 


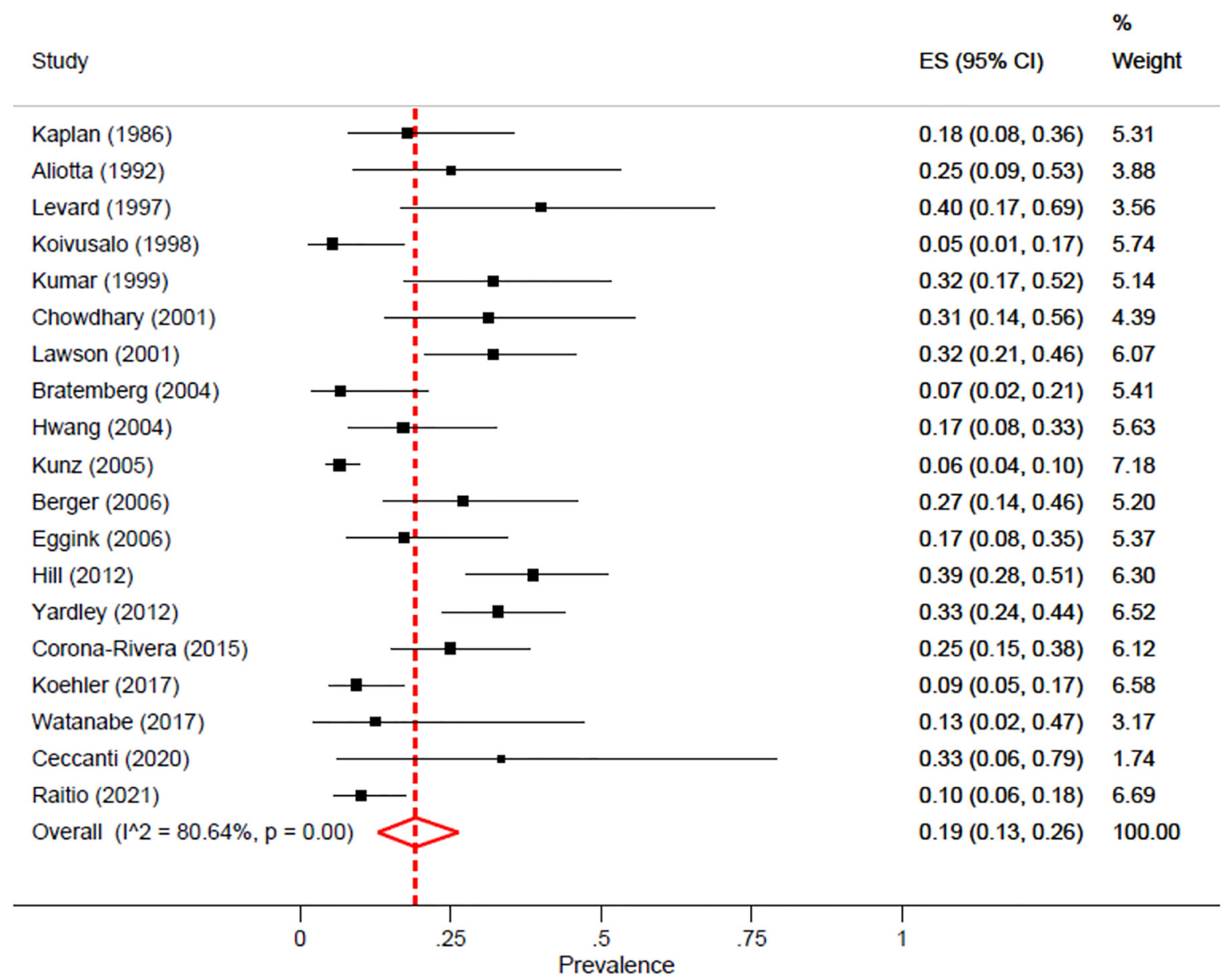

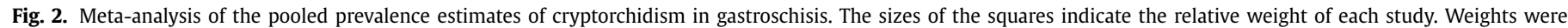
derived from random-effects analysis. Bars, 95\% confidence interval (CI). ES, estimated proportion.

In this latter case, the initially prolapsed UDT was found into the contralateral hemiscrotum (crossed testicular ectopy).

Early orchiopexy was most frequently performed for prolapsed testes (11/34 prolapsed testes, 3/63 nonpalpable testes, 0/23 palpable testes; $p=<0.0001$ for trend) (Fig. 5). Nonoperative management was initially adopted in 104 (86.6\%) testes, including remaining 21 prolapsed testes that were simply relocated into the abdomen for potential spontaneous descent.

Fifty-five $(52.8 \%)$ testes descended spontaneously to the scrotum, without significant difference across the 3 subgroups (13/23 palpable, 33/60 nonpalpable, 9/21 prolapsed, $p=0.37$ for trend). Time of spontaneous descent was available for 26 testes, which were ascertained in scrotal position between 1 and 27 months of life (median, 11 months of life). ${ }^{13,20,27,31}$

Of the remaining 49 (47\%) testes, 10 (20.4\%) were primarily removed for impossible orchiopexy (4), ${ }^{14,21}$ atrophic $(2)^{20}$ or remnant/absent testis (4), ${ }^{14,19}$ resulting in anorchia in 1 patient. ${ }^{21}$ Thirty-five (71.4\%) testes underwent orchiopexy between 7 months and 9 years of life (median, 16.5 months of life), resulting in 25 testes normal in size and position. Finally, 4 (8.1\%) testes were still awaiting orchiopexy.

Overall, of the 49 orchiopexies performed, 18 (36.7\%) testes had an unfavorable outcome, including testicular hypoplasia (8), atrophy (7), and recurrent UDT (3). Such dismal outcome did not correlate with timing of orchiopexy (57\% early vs $28.6 \%$ later orchiopexy, $p=0.1$, nor with the original location of UDT (8/18 prolapsed, $9 / 23$ nonpalpable, $1 / 8$ palpable, $p=0.15$ for trend). Ten $(20.4 \%)$ orchiopexies were performed using the Fowler-Stephens procedure, either single-stage ( 6 nonpalpable testes) or two-stage ( 3 prolapsed and 1 palpable testes). Only 4 of these testes had a successful outcome, regardless of the used procedure. One patient with a prolapsed UDT descended spontaneously into the scrotum, underwent repair of ipsilateral inguinal hernia that developed at 3 years of age. ${ }^{31}$ Given the high scrotal position of the testis, the spermatic cord was freed from surrounding adherences to improve testis location into the scrotum without undue tension. During this procedure, a well-formed gubernaculum was documented and preserved.

One patient required contralateral orchiopexy for an ascending testis at 1 year of age. ${ }^{10}$ When including also the 12 testes/remnants primarily removed or absent, a total of 30 of the $61(49.2 \%)$ explored testes had a dismal outcome (13/23 prolapsed testes, $16 / 30$ nonpalpable testes, $1 / 8$ palpable testes, $p=0.07$ for trend). Finally, when considering the whole number of UDT in gastroschisis and excluding the 4 testes still awaiting orchiopexy, the overall dismal outcome rate was $25.8 \%$ (30/116), most frequently occurring for prolapsed and nonpalpable testes (13/32 prolapsed testes, $16 / 63$ nonpalpable testes, $1 / 21$ palpable testes, $p=0.02$ for trend).

\section{Discussion}

Twenty percent of patients with gastroschisis may present prolapsed reproductive organs besides bowels, being testis much less frequently involved than ovary (9.3\% vs $30.6 \%){ }^{25}$ 


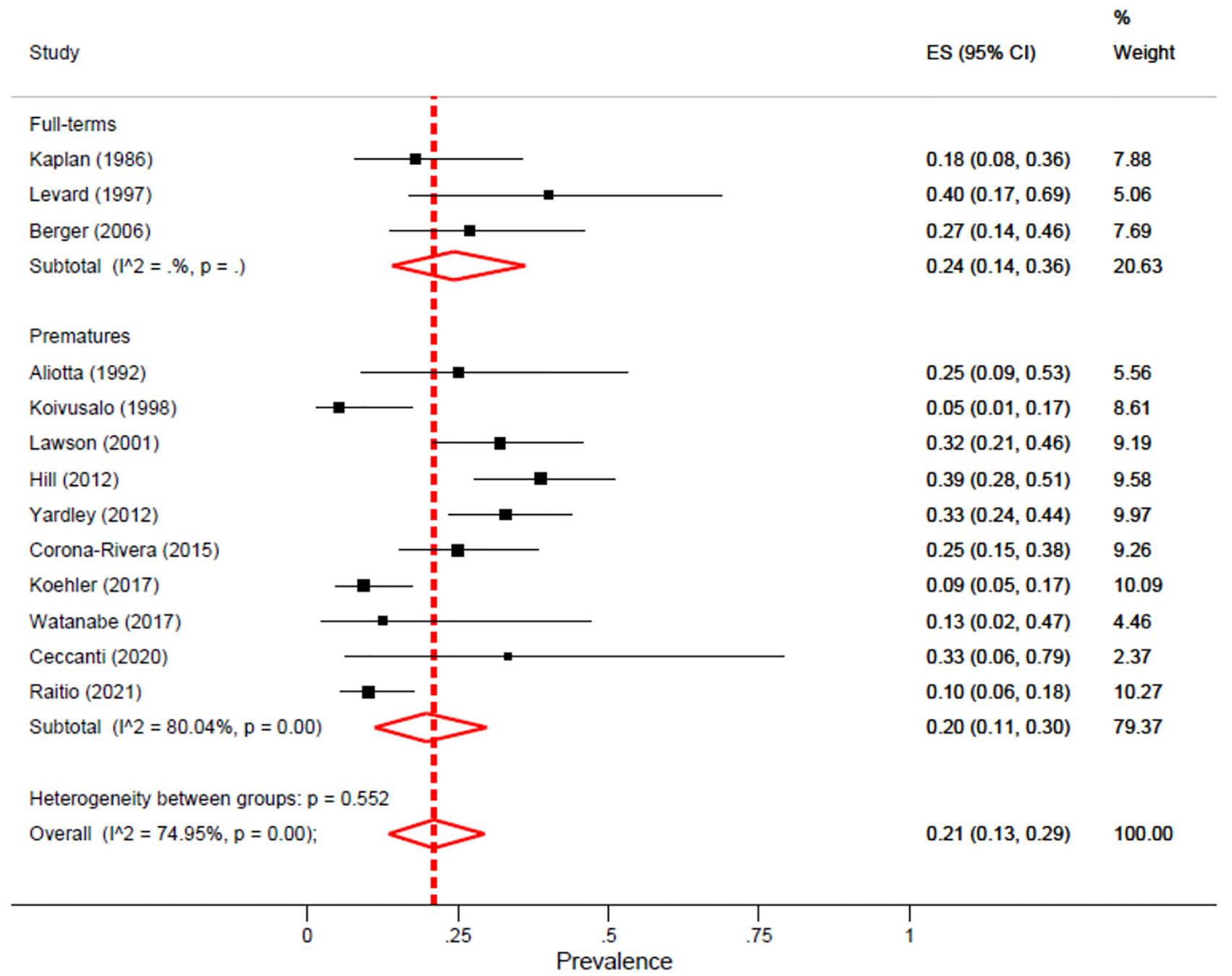

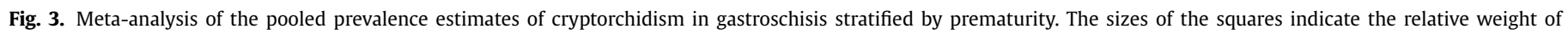
each study. Weights were derived from random-effects analysis. Bars, 95\% confidence interval (CI). ES, estimated proportion.

Generally, cryptorchidism plays a minor role at birth, because the first attention is focused on the life-threatening anomalies related to gastroschisis. Therefore, less is known about the fate of the undescended testis. To date, there are no consensus or guidelines on the treatment modality that offers the best chance for testicular salvage and preservation of endocrine function and fertility in this specific population.

We found that prevalence of cryptorchidism in the male gastroschisis population varied from 5 to $40 \%$, with a pooled prevalence estimate of $19 \%$ ( $95 \%$ CI $13-26 \%$ ). Notably, several prospective clinical studies have addressed the epidemiology of cryptorchidism in otherwise healthy males over the past six decades, with a birth rate of cryptorchidism varying between $1.6 \%$ and $9 \%{ }^{32} \mathrm{Al}-$ though these studies suggested an increasing trend and geographical differences, cryptorchidism prevalence appears to be significantly higher in the gastroschisis male population. Using some large series on general population risk for UDT, 2 previous studies extrapolated a relative risk for cryptorchidism at birth in gastroschisis patients of 3.1 (95\% CI 1.1-8) and 4.37 (95\% CI 1.6-11.9), respectively. ${ }^{7,9}$

Notably, prematurity (i.e., < 37 weeks) is a known risk factor for cryptorchidism in otherwise healthy males, with a higher prevalence ranging from 17 to $30 \% .^{32}$ Likewise, the close association between gastroschisis and spontaneous premature birth is also well known. ${ }^{33}$ As such, prematurity could potentially explain the higher prevalence of cryptorchidism in gastroschisis. Interestingly, we found a similar pooled prevalence of cryptorchidism in full-term versus premature babies with gastroschisis (Fig. 3). However, the lack of difference in our meta-analysis may be biased by the small number of included studies, which are all retrospective and with a small number of patients in most of them. Therefore, in the absence of any prospective studies, it is not clear whether UDT is associated with gastroschisis independently of prematurity.

Another explanation for the higher prevalence of UDT in gastroschisis, relies on the potential role of intra-abdominal pressure in the mechanism of testicular descent. First described by Gier and Marion in 1969, this theory states that, during gestation, abdominal organs add pressure against the testis, which is expelled from its original intra-abdominal location into the scrotum. ${ }^{34}$ Advocates of this theory believe that abdominal wall defects are associated with a lower intra-abdominal pressure that impedes the testis to descend into the scrotum in both clinical and experimental studies. ${ }^{7,35}$ Although direct measurements of intra-abdominal pressure during the process of testicular descent have not yet conducted in any animal model, including man, an indirect support to the intra-abdominal pressure theory comes from the high prevalence of nonpalpable UDT found in gastroschisis.

It is common knowledge that approximately $75 \%$ of UDT are usually palpable. ${ }^{37,38}$ Contrary to this general trend, we found that UDT in gastroschisis were palpable in less than $20 \%$ of cases, 


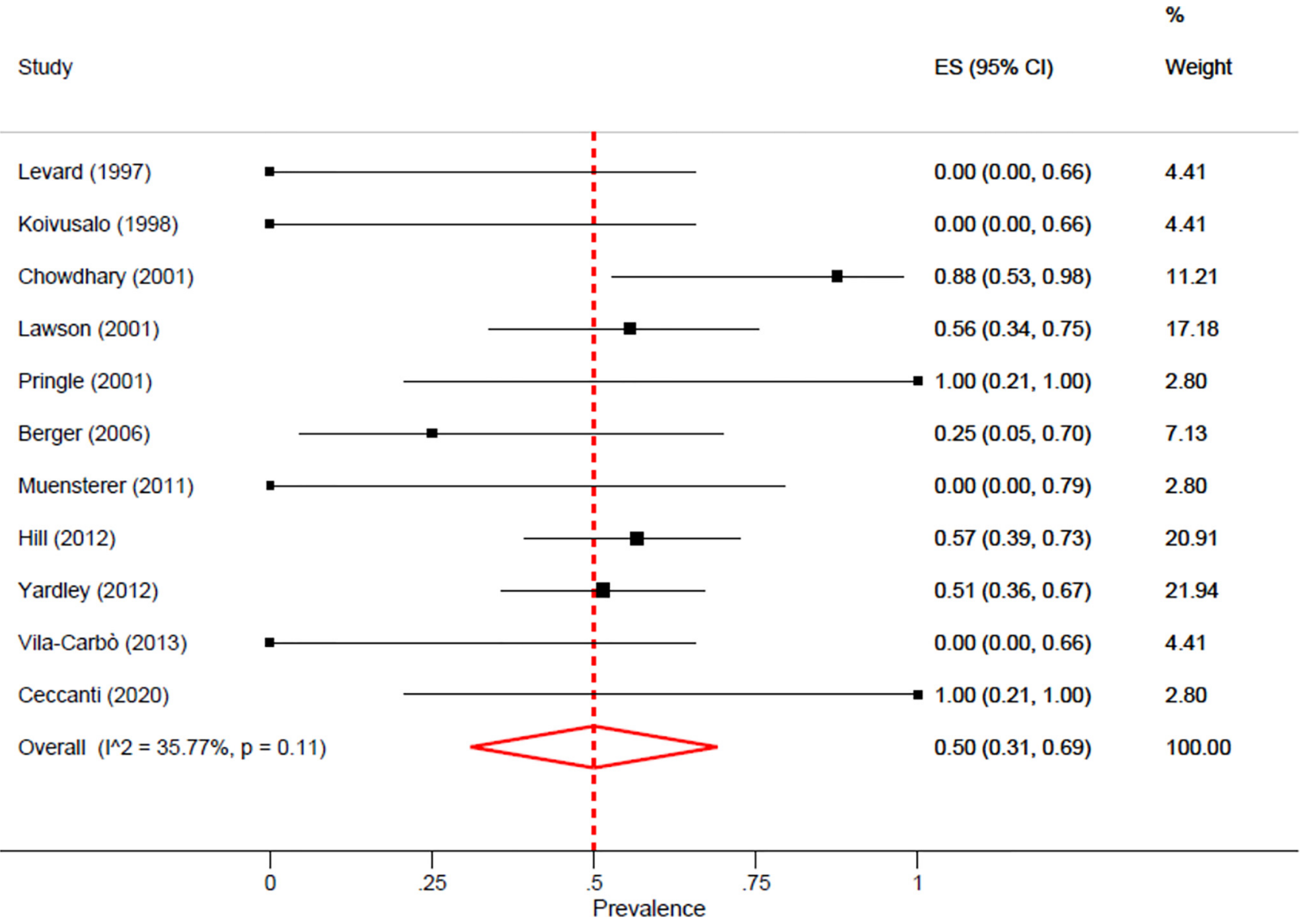

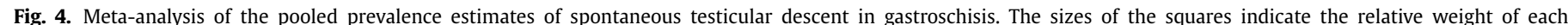
study. Weights were derived from random-effects analysis. Bars, 95\% confidence interval (CI). ES, estimated proportion.
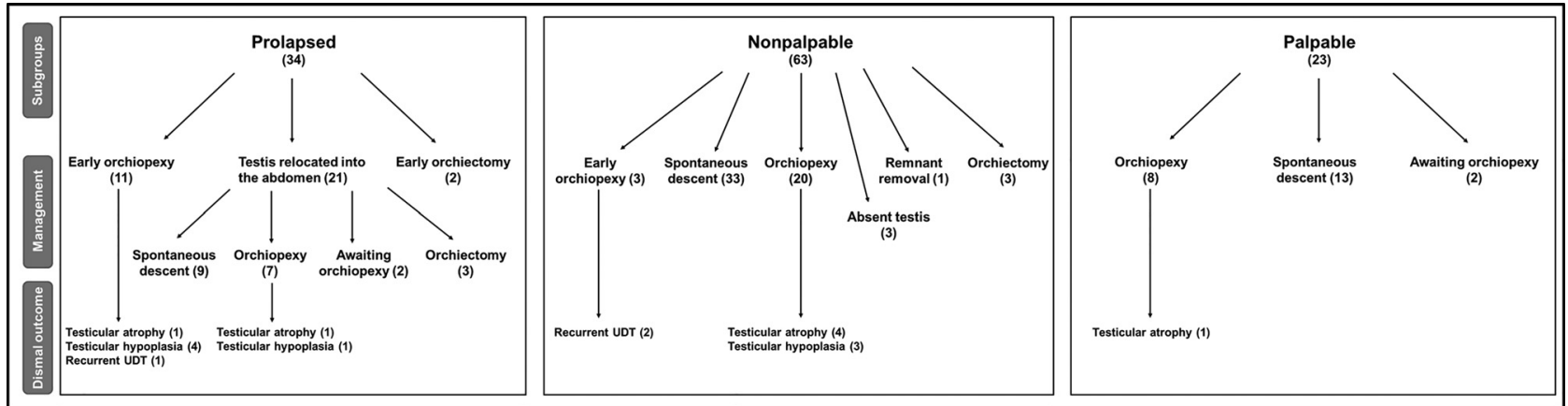

Fig. 5. Management and dismal outcome of cryptorchidism associated with gastroschisis clustered according to the UDT original location.

whereas the prevalence of nonpalpable UDT resulted as high as 52.5\%. Such inverse rates become even more considerable if the percentage of prolapsed UDT (28.3\%) is counted. Notably, the latter UDT subgroup belongs solely to gastroschisis and is characterized by an extra-abdominal location of the testis, which is prolapsed outside of the abdominal wall, beside the extruded intestines.

While the gubernaculum unequivocally serves as a rudder guiding the testis into the scrotum, we concur with others, that intraabdominal pressure may also play an important role during the testicular descent process, acting either directly to the testis or indirectly by creating the tip of the processus vaginalis. ${ }^{39,40}$

However, some studies conducted on congenital or surgically created abdominal wall defects have shown that an intact abdominal wall may not be a prerequisite for testicular descent. ${ }^{11,36}$ In support of this belief, we found that all patients with unilateral UDT included in this review had their contralateral testes normally descended in the scrotum, and that the rate of bilateral UDT in gastroschisis population (27.6\%) is well in line with reported rates in otherwise healthy UDT populations, ranging from 30 to $39 \%{ }^{1,2}$ Therefore, both physical forces and hormonal factors, in tandem with gubernaculum migration, are essential in testicular descent. As such, a defective implantation or loss of the gubernaculum, along with premature closure of the PPV or simply the formation of obstructing adhesions at the internal inguinal ring or between testes and adjacent structures, have been brought into play as potentially adverse factors interfering with testis descent. ${ }^{8}$

Notably, Attah and Hutson demonstrated in rats that in case of an abdominal wall defect (i.e., lower intrabdominal pressure) and a 
free testis (i.e., proximal gubernaculum attachment transected), the likelihood of testis descent significantly decreased to $42 \%$, given the less chances of the testis to occupy entrance to processus vaginalis. ${ }^{39}$ Likewise, we found that the subgroup of prolapsed testes in gastroschisis, which offers a unique human model sharing close anatomical similarities to the aforementioned experimental model, showed a spontaneous testicular descent in only $43 \%$ of cases. Interestingly, one patient of this peculiar subgroup had his UDT incidentally found into the contralateral hemiscrotum during inguinal hernia repair. ${ }^{20}$ Such condition, known as crossed testicular ectopy, is believed to be related to unilateral abnormality of the gubernaculum. Notably, this phenomenon has been also observed in rats after excision of ipsilateral gubernaculum. ${ }^{35}$

Nonetheless, we found that a well-formed gubernaculum was demonstrated at the time of inguinal hernia repair in at least 3 patients with an originally prolapsed UDT. ${ }^{10,27,31}$ Moreover, opposite to previous observation of no existing literature on inguinal hernia development in infants with gastroschisis, ${ }^{8}$ we counted at least 4 (4.2\%) inguinal hernias in present review, ${ }^{10,20,27,31}$ with an overall prevalence rate similar to that reported in the general male population.

All these findings support the hypothesis that when an originally prolapsed UDT is simply relocated into the abdominal cavity or an intrabdominal UDT is left undisturbed, gubernaculum and PPV formation may occur, thus contributing to a belated but otherwise normal testicular descent.

In this review, we found an overall spontaneous descent rate of $52.4 \%$, with no significant differences across the 3 UDT subgroups. Notably, such a spontaneous descent rate in gastroschisis patients seems significantly lower than the $69.6 \%$ to $75 \%$ rate reported in literature-derived controls at 1 year of age. ${ }^{41-43}$ We suppose that the higher proportion of nonpalpable UDT in this population may in part explain such a lower rate of spontaneous testicular descent. Moreover, we found that also palpable UDT spontaneously descended in less than $60 \%$ of cases. This further supports the hypothesis that, given the well-known high propensity of adhesion formation in gastroschisis patients, also adhesions between testis and adjacent structures play a role among the multifactorial agents interfering with the path of testis descent.

As far as it concerns the management of UDT in gastroschisis patients, this review found a lack of consensus regarding optimal timing of orchiopexy, with 16 (13.3\%) UDT undergoing operative management within first 3 months of life. Notably, such a deviation from current UDT management recommendations ${ }^{44}$ involved 3 non-palpable and 13 prolapsed UDT. The predominance of prolapsed UDT deemed candidates for early operative management might justify such a discordant practice, given the scanty available information on this rare UDT subgroup, belonging to gastroschisis patients only. Advocates of early orchiopexy argued that, unlike patients with UDT alone, gastroschisis patients tend to form multiple abdominal adhesions that may render orchiopexy at later stage more troublesome or impossible, especially because they may limit the use of laparoscopy for persisting intrabdominal UDT. ${ }^{19}$ Additionally, they claimed that early orchiopexy offers excellent exposure, easy mobilization, and better chances of testicular preservation. 8,10 Finally, when one-stage orchiopexy is not feasible because of inadequate length of the spermatic cord, they recommend mobilization and fixation of the UDT as close as possible to the internal inguinal ring. ${ }^{19}$

In contrast, the remainder of UDT associated with gastroschisis were managed according with current guidelines, thus favoring an initial wait and see strategy, especially considering the caveat that an attempt of early manipulation of UDT and/or division of spermatic vessels are at greater risk of compromising its very fragile vascular supply. ${ }^{13,14,21}$ This review showed that simply relocating prolapsed UDT into the abdomen or leaving undisturbed an intra- abdominal UDT at the time of gastroschisis repair allows normal spontaneous descent in at least $50 \%$ of cases, without precluding later orchidopexy. Additionally, almost a third of non-palpable UDT may eventually reach the inguinal canal, avoiding the need of entering the abdomen during later orchiopexy. ${ }^{20}$

In this review, orchiopexy was successful in $63.2 \%$ (31/49) of cases. Notably, such a success rate was significantly lower than the 81.4\% (759/932) extrapolated from a large, literature-derived cohort of patients undergoing orchiopexy from 1985 onwards, who received the same types of orchiopexy performed in this review (95\% CI 0.62-0.96; $p=0.004) .{ }^{45}$ Although we did not find any correlation between successful rate of orchiopexy and timing or original UDT location in gastroschisis patients, subgroup analysis revealed that only neonatal orchiopexy was associated with significantly lower success rate (43\%) than that of literature-derived UDT controls $(6 / 14$ vs $759 / 932 ; p=0.001){ }^{45}$

The overall dismal outcome of UDT in gastroschisis was $25.8 \%$ (30/116), affecting almost exclusively prolapsed and nonpalpable testes. Notably, such a high dismal outcome consisted of primary nonviable testes (6\%), testes removed because were judged impossible for orchiopexy (4.3\%), and morbidity after orchiopexy (15.5\%). As far as concerns the high rate of orchiectomy performed for impossible orchiopexy, although we do not have enough information to fully understand the reasons of such a subjective choice, we believe that the decision of impossible orchiopexy should be discouraged at least in the neonatal period, given the possibility to rescue these testes by staged procedures. The post-operative morbidity after orchiopexy in gastroschisis patients, when excluding neonatal orchiopexies, was again comparable to that reported following orchiopexies performed for intrabdominal testes only, regardless of the used technique. ${ }^{46}$

Among the limitations of the present review, we acknowledge the retrospective nature of the included studies, which were also small and often underpowered. Nevertheless, the included studies scored relatively well on validated tools used for quality assessment. ${ }^{5,6}$ Additionally, we supplemented our meta-analysis with confidence intervals, in an attempt to calculate the bias of the large heterogeneity found, which we estimated using the $\mathrm{I}^{2}$ metric. However, meta-analyses performed for rare diseases and small populations are known to present specific challenges, including a paucity of high certainty evidence to set a management standardization. Despite its potential limitations, to our knowledge present review elicits and synthesizes available evidence on this rarely reported association involving a common condition such UDT and a rare disease such gastroschisis.

\section{Conclusions}

Prevalence of cryptorchidism in gastroschisis patients seems higher than that reported in the general population, and it is likely underreported. Opposite to the general population, such association has a lower likelihood of spontaneous testis descent. However, given the $50 \%$ chance of spontaneous descent regardless of the original testis location, we believe that the same initial wait and see policy of current UDT management algorithm may be safely adopted also for UDT associated with gastroschisis, including prolapsed testes that should be simply relocated into the abdomen.

UDT associated with gastroschisis carries a significant overall mediocre testicular outcome. Such a dismal outcome seems to reflect the most unfavorable presentation of cryptorchidism in gastroschisis, which is represented by originally intrabdominal or prolapsed UDT in the majority of cases. Neonatal orchiopexy is associated with suboptimal outcome and should be discouraged, as well as primary orchiectomy of viable testis.

We trust that shedding light on UDT associated with gastroschisis will turn present data into critical actionable insights that 
may guide health-care professionals to optimal management and parental information when coming across such a rarely reported, but frequently occurring association.

\section{Declaration of Competing Interest}

None.

\section{References}

[1] Boisen KA, Kaleva M, Main KM. Difference in prevalence of congenital cryptorchidism in infants between two Nordic countries. Lancet 2004;363:1264. doi:10.1016/S0140-6736(04)15998-9.

[2] Ghirri P, Ciulli C, Vuerich M. Incidence at birth and natural history of cryptorchidism: a study of 10,730 consecutive male patients. J Endocrinol Invest 2002;25:709, doi:10.1007/BF03345105.

[3] Moher D, Liberati A, Tetzlaff J. Preferred reporting items for systematic reviews and meta-analyses: the PRISMA statement. PLoS Med 2009;6:e1000097. doi:10.1371/journal.pmed1000097.

[4] OCEBM Levels of Evidence Working Group. "'The Oxford 2011Levels of Evidence. Oxford Centre of Evidence-Based Medicine; 2020 http://www.cebm.net/index.aspx?o=5653.

[5] Slim K, Nini E, Forestier D. Methodological index for non-randomized studies (MINORS): development and validation of a new instrument. ANZ J Surg 2003;73:712. doi:10.1046/j.1445-2197.2003.02748.x

[6] Agha RA, Borrelli MR, Farwana R. The SCARE 2018 statement: updating consensus surgical case report (SCARE) guidelines. Int J Surg 2018;60:132. doi:10. 1016/j.ijsu.2018.10.028

[7] Kaplan LM, Koyle MA, Kaplan GW. Association between abdominal wall defects and cryptorchidism. J Urol 1986;136:645. doi:10.1016/s0022-5347(17)45003-8.

[8] Gauderer MW. Gastroschisis and extraabdominal ectopic testis: simultaneous repair. J Pediatr Surg 1987;22:657. doi:10.1016/s0022-3468(87)80121-5.

[9] Aliotta PJ, Piedmonte M, Karp M. Cryptorchidism in newborns with gastroschisis and omphalocele. Urology 1992;40:84. doi:10.1016/0090-4295(92)90445-3.

[10] Levard G, Laberge JM. The fate of undescended testes in patients with gas troschisis. Eur J Pediatr Surg 1997; 7:163. doi:10.1055/s-2008-1071081.

[11] Koivusalo A, Taskinen S, Rintala RJ. Cryptorchidism in boys with congenital abdominal wall defects. Pediatr Surg Int 1998;13:143. doi:10.1007/ s003830050269.

[12] Kumar RK, Shi EC, Duffy B. Cisapride and caesarean section: their role in babies with gastroschisis. J Paediatr Child Health 1999;35:181. doi:10.1046/j. 1440-1754.1999.t01-1-00339.x.

[13] Chowdhary SK, Lander AD, Buick RG. The primary management of testic ular maldescent in gastroschisis. Pediatr Surg Int 2001;17:359. doi:10.1007| s003830000571.

[14] Lawson A, de La Hunt MN. Gastroschisis and undescended testis. J Pediatr Surg 2001:36:366. doi:10.1053/jpsu.2001.20718.

[15] Brantberg A, Blaas HG, Salvesen KA. Surveillance and outcome of fetuses with gastroschisis. Ultrasound Obstet Gynecol 2004;23:4. doi:10.1002/uog.950.

[16] Hwang PJ, Kousseff BG. Omphalocele and gastroschisis: an 18-year review study. Genet Med 2004;6:232. doi:10.1097/01.gim.0000133919.68912.a3.

[17] Kunz LH, Gilbert WM, Towner DR. Increased incidence of cardiac anomalies in pregnancies complicated by gastroschisis. Am J Obstet Gynecol 2005;193:1248. doi:10.1016/j.ajog 2005.05.080.

[18] Eggink BH, Richardson CJ, Malloy MH. Outcome of gastroschisis: a 20-year case review of infants with gastroschisis born in Galveston, Texas. J Pediatr Surg 2006:41:1103. doi:10.1016/j.jpedsurg.2006.02.008

[19] Berger AP, Hager J. Management of neonates with large abdominal wall defects and undescended testis. Urology 2006;68:175. doi:10.1016/j.urology.2006. 01.091.

[20] Hill SJ, Durham MM. Management of cryptorchidism and gastroschisis. J Pediatr Surg 2011;46:1798. doi:10.1016/j.jpedsurg.2011.01.017.

[21] Yardley IE, Bostock E, Jones MO. Congenital abdominal wall defects and testicular maldescent-a 10-year single-center experience. J Pediatr Surg 2012;47:1118. doi:10.1016/j.jpedsurg.2012.03.011.
[22] Vila-Carbó JJ, Hernández E, Ayuso L. Impact in our environment of a gastroschisis therapeutic management protocol. Cir Pediatr 2008;21:203.

[23] Corona-Rivera JR, Nieto-García R, López-Marure E. Associated congenital anomalies in infants with isolated gastroschisis: a single-institutional experience. Am J Med Genet A 2016:316 170A. doi:10.1002/ajmg.a.37433.

[24] Watanabe S, Suzuki T, Hara F. Omphalocele and gastroschisis in newborns: over 16 Years of experience from a single clinic. J Neonatal Surg 2017;6:27. doi:10.21699/jns.v6i2.530.

[25] Koehler SM, Szabo A, Loichinger M. The significance of organ prolapse in gastroschisis. J Pediatr Surg 2017;52:1972. doi:10.1016/j.jpedsurg.2017.08.066.

[26] Raitio A., Syvänen J., Tauriainen A., Congenital abdominal wall defects and ryptorchidism: a population-based study. Pediatr Surg Int. 2021 Jan 31. doi: 10.1007/s00383-021-04863-9.

[27] Pringle KC. Testicular proximity can induce gubernaculum formation after delivery. J Pediatr Surg 2001;36:1708. doi:10.1053/jpsu.2001.27969.

[28] Wakefield MR, Steinbecker KM, Krambeck AE. Primary surgical repair of combined gastroschisis and bladder exstrophy. J Pediatr Surg 2002;37:1634. doi:10. 1053/jpsu.2002.36201.

[29] Muensterer OJ. Laparoscopic single-stage Fowler-Stephens orchidopexy in a case of orchidogastric fusion. Urology 2011;78:687. doi:10.1016/j.urology.2010. 12.032

[30] Patel RV, Sinha CK, More B, Rajimwale A. Closing left gastroschisis with vanishing left testis. BMJ Case Rep 2013:11 pii: bcr2013200683. doi:. doi:10.1136 bcr-2013-200683.

[31] Ceccanti S, Piacenti S, Cozzi DA. Extra-abdominal cryptorchidism associated with gastroschisis and impacted urethral calculus: two uncommon urologic conditions in one patient. Urology 2020;142:205 doi:. doi:10.1016/j.urology. 2020.04.034

[32] Virtanen HE, Toppari J. Epidemiology and pathogenesis of cryptorchidism. Hum Reprod Update 2008;14:49. doi:10.1093/humupd/dmm027.

[33] Baer RJ, Chambers CD, Ryckman KK. High risk of spontaneous preterm birth among infants with gastroschisis. Am J Med Genet A 2019;179:37. doi:10.1002/ ajmg.a.60675.

[34] Gier H.T., Marion G.B. Development of mammalian testes and genital ducts Biol Reprod. 1969 Jun;1:Suppl 1:1. doi: 10.1095/biolreprod1.supplement_1.1.

[35] Frey HL, Rajfer J. Role of the gubernaculum and intraabdominal pressure in the process of testicular descent. J Urol 1984;131:574. doi:10.1016/s0022-5347(17) 50507-8

[36] Quinlan DM, Gearhart JP, Jeffs RD. Abdominal wall defects and cryptorchidism: an animal model. J Urol 1988;140:1141. doi:10.1016/s0022-5347(17)41982-3.

[37] Braga LH, Lorenzo AJ, Romao RLP. Canadian urological association-pediatric urologists of Canada (CUA-PUC) guideline for the diagnosis, management, and followup of cryptorchidism. Can Urol Assoc J 2017;11:E251. doi:10.5489/cuaj. 4585.

[38] Cendron M, Huff DS, Keating MA. Anatomical, morphological and volumetric analysis: a review of 759 cases of testicular maldescent. J Urol 1993;149:570. doi:10.1016/s0022-5347(17)36151-7.

[39] Attah AA, Hutson JM. The role of intra-abdominal pressure in cryptorchidism. J Urol 1993;150:994. doi:10.1016/s0022-5347(17)35672-0.

[40] Hutson JM, Hasthorpe S, Heyns CF. Anatomical and functional aspects of testicular descent and cryptorchidism. Endocr Rev 1997;18:259. doi:10.1210/edrv. 18.2.0298.

[41] Thong M, Lim C, Fatimah H. Undescended testes: incidence in 1,002 consecutive male infants and outcome at 1 year of age. Pediatr Surg Int 1998;13:37. doi:10.1007/s003830050239.

[42] Berkowitz GS, Lapinski RH, Dolgin SE. Prevalence and natural history of cryptorchidism. Pediatrics 1993;92:44

[43] Preiksa RT, Zilaitiene B, Matulevicius V. Higher than expected prevalence of congenital cryptorchidism in Lithuania: a study of 1204 boys at birth and 1 year follow-up. Hum Reprod 2005;20:1928 doi:. doi:10.1093/humrep/deh887.

[44] Chan E. Wayne C. Nasr A. FRCSC for Canadian association of pediatric surgeon evidence-based resource: ideal timing of orchiopexy: a systematic review. Pediatr Surg Int 2014;30:87 doi:. doi:10.1007/s00383-013-3429-y.

[45] Docimo SG. The results of surgical therapy for cryptorchidism: a literature review and analysis. J Urol 1995;154:1148.

[46] Stec AA, Tanaka ST, Adams MC. Orchiopexy for intra-abdominal testes: factors predicting success. J Urol 2009;182:1917 doi: 10.1016/j.juro.2009.03.069. 